\title{
ANTOCIANINAS EM EXTRATOS VEGETAIS: APLICAÇÃO EM TITULAÇÃO ÁCIDO-BASE E IDENTIFICAÇÃO VIA CROMATOGRAFIA LÍQUIDA/ESPECTROMETRIA DE MASSAS
}

\author{
Wesson Guimarães, Maria Isabel Ribeiro Alves e Nelson Roberto Antoniosi Filho* \\ Instituto de Química, Universidade Federal de Goiás, CP 131, 74001-970 Goiânia - GO, Brasil
}

Recebido em 26/10/11; aceito em 12/3/12; publicado na web em 20/7/12

\begin{abstract}
ANTHOCYANINS IN NATURAL EXTRACTS: APPLICATION IN ACID-BASE TITRATION AND IDENTIFICATION BY LIQUID CHROMATOGRAPHY/MASS SPECTROMETRY. Anthocyanins extracted from picao, quaresmeira, petunia, flamboyant, purple ipe, lobeira, pata de vaca, jaboticaba, purple cabbage and jambul were evaluated as natural acid-base indicators. Anthocyanins in extracts were identified using HPLC/MS. Clear, rapid change in color at final-point titration was observed for extracts but only picao showed strong change in $\mathrm{pH}$. Indirect determination of carbonate in limestone using a natural indicator was performed and results compared with phenolphthalein indicator and potentiometer titration. Optimal results were obtained with picao but other extracts showed good accuracy and precision.
\end{abstract}

Keywords: pH; anthocyanins; HPLC.

\section{INTRODUÇÃO}

As antocianinas (do grego: anthos = flores; kianos = azul), pertencentes à classe dos flavonoides, são os pigmentos responsáveis pela coloração azul, violeta, vermelha e rosa exibida por flores e frutos. ${ }^{1,2}$ Todas as antocianinas são derivadas da estrutura básica do cátion flavilium (Figura 1), deficiente em elétrons e, portanto, muito reativo.<smiles>[R3]c1cc2c(O)c([R])c(O)cc2[o+]c1-c1cc([R])c(O)c([R])c1</smiles>

Figura 1. Estrutura básica do cátion flavilium

As antocianinas apresentam-se frequentemente associadas a açúcares, ligados aos grupos hidroxila $\mathrm{OH}^{-}$. Quando livres desses açúcares são chamadas de antocianidinas ou agliconas e as que ocorrem com maior frequência na natureza estão apresentadas na Tabela $1 .^{3}$

A propriedade das antocianinas apresentarem cores diferentes, dependendo do $\mathrm{pH}$ do meio em que se encontram, torna possível o seu uso como indicadores naturais de $\mathrm{pH}$ em determinações analíticas quantitativas. ${ }^{4,5}$ Algumas das vantagens que podem ser apontadas em relação à utilização de pigmentos naturais, em substituição aos indicadores convencionais, incluem o fato dos indicadores naturais estarem disponíveis em tecidos vegetais de várias espécies de plantas facilmente encontradas na natureza. Além disso, por serem naturalmente encontrados no meio ambiente, esses corantes causam menor impacto ambiental quando descartados. Quimicamente, o fato de serem consideravelmente solúveis em água facilita a preparação do indicador na forma de solução e acelera sua decomposição no meio ambeinte.

Assim, avaliou-se o potencial como indicador ácido-base dos extratos de casca de jabuticaba (Myrciaria cauliflora Berg.), jambolão (Syzygium cuminii Skeels), flores de petúnia (Petunia x hibrida Hort.

*e-mail: nelson@quimica.ufg.br
Tabela 1. Nomes e grupos substituintes de antocianidinas mais frequentes na natureza

\begin{tabular}{lccccc}
\hline Aglicona & $\mathrm{R}_{1}$ & $\mathrm{R}_{2}$ & $\mathrm{R}_{3}$ & $\mathrm{R}_{4}$ & $\begin{array}{c}\text { Massa } \\
\text { Molecular } \\
\text { (daltons) }\end{array}$ \\
\hline Cianidina & $\mathrm{OH}$ & $\mathrm{H}$ & $\mathrm{OH}$ & $\mathrm{H}$ & 287 \\
Tricetidinina & $\mathrm{OH}$ & $\mathrm{OH}$ & $\mathrm{H}$ & $\mathrm{H}$ & 287 \\
Aurantidina & $\mathrm{H}$ & $\mathrm{H}$ & $\mathrm{OH}$ & $\mathrm{OH}$ & 287 \\
Delfinidina & $\mathrm{OH}$ & $\mathrm{OH}$ & $\mathrm{OH}$ & $\mathrm{H}$ & 303 \\
6-Hidroxicianidina & $\mathrm{OH}$ & $\mathrm{H}$ & $\mathrm{OH}$ & $\mathrm{OH}$ & 303 \\
Malvidina & $\mathrm{OCH}_{3}$ & $\mathrm{OCH}$ & $\mathrm{OH}$ & $\mathrm{H}$ & 331 \\
Pelargonidina & $\mathrm{H}$ & $\mathrm{H}$ & $\mathrm{OH}$ & $\mathrm{H}$ & 271 \\
Luteolidina & $\mathrm{OH}$ & $\mathrm{H}$ & $\mathrm{H}$ & $\mathrm{H}$ & 271 \\
Peonidina & $\mathrm{OCH}_{3}$ & $\mathrm{H}$ & $\mathrm{OH}$ & $\mathrm{H}$ & 301 \\
Petunidina & $\mathrm{OCH}_{3}$ & $\mathrm{OH}$ & $\mathrm{OH}$ & $\mathrm{H}$ & 317 \\
\hline
\end{tabular}

ex. Vilm.), flores do flamboyant (Delonix regea Rafin.), flores de pata de vaca (Bauhinia variegata L.),flores de picão (Bidens gardneri Baker), flores de ipê roxo (Tabebuia impetiginosa (Mart.) Standl.), flores de lobeira (Solanum lycocarpum A. St. Hil.), flores de quaresmeira (Tibouchina granulosa Cogn.) e repolho roxo (Brassica oleracea L.). As antocianinas dos extratos foram purificadas utilizando extração em fase sólida (SPE - Solid Phase Extraction) e identificadas por cromatografia líquida acoplada à espectrometria de massas (HPLC/ MS - High Performance Liquid Chromatography/Mass Spectrometry).

\section{PARTE EXPERIMENTAL}

\section{Preparo do extrato}

Os tecidos das plantas avaliadas foram coletados na região de Goiânia, Goiás. O extrato de cada espécie de planta foi obtido imergindo-se $50 \mathrm{~g}$ de pétalas em $500 \mathrm{~mL}$ de álcool etílico comercial $\left(96^{\circ} \mathrm{GL}\right)$ por um período aproximado de $2 \mathrm{~h}$. Em seguida, o extrato foi filtrado em algodão e submetido à rotoevaporação em temperatura inferior a $60^{\circ} \mathrm{C}$. O extrato bruto aquoso foi transferido para balão de 
fundo redondo, com capacidade para $125 \mathrm{~mL}$. Este balão foi adaptado a um liofilizador (Labconco modelo 77500), transferido para frasco de vidro de cor âmbar e conservado sob temperatura de aproximadamente $10^{\circ} \mathrm{C}$. Para as duas espécies de frutos, jabuticaba e jambolão, e para o repolho roxo o procedimento foi similar, diferindo apenas na quantidade de amostra (300 g).

\section{Preparo de soluções}

A partir dos extratos liofilizados foram preparadas soluções indicadoras em água, conforme mostrado na Tabela 2. Prepararamse também soluções indicadoras de azul bromofenol em água e de fenolftaleína em isopropanol. As soluções foram conservadas em geladeira, com temperatura controlada para $\pm 10^{\circ} \mathrm{C}$.

Tabela 2. Concentração das soluções indicadoras

\begin{tabular}{lccc}
\hline Indicador & $\begin{array}{c}\text { Massa de extrato } \\
\text { liofilizado }(\mathrm{g})\end{array}$ & $\begin{array}{c}\text { Volume de } \\
\text { solução }(\mathrm{mL})\end{array}$ & $\begin{array}{c}\text { Concentração } \\
(\mathrm{g} \mathrm{mL})\end{array}$ \\
\hline Jabuticaba & 0,5100 & 50,0 & 0,010 \\
Jambolão & 0,6397 & 50,0 & 0,013 \\
Petúnia & 0,4000 & 50,0 & 0,0080 \\
Flamboyant & 0,4250 & 100,0 & 0,0043 \\
Pata de Vaca & 0,2200 & 50,0 & 0,0044 \\
Flor do Picão & 0,2029 & 50,0 & 0,0041 \\
Repolho Roxo & 0,5000 & 50,0 & 0,010 \\
Quaresmeira & 1,7440 & 50,0 & 0,035 \\
Flor do Ipê Roxo & 0,6730 & 100,0 & 0,0067 \\
Flor da Lobeira & 0,5947 & 50,0 & 0,012 \\
Fenolftaleína & 0,5000 & 50,0 & 0,010 \\
Azul de Bromofenol & 0,0200 & 50,0 & 0,00040 \\
\hline
\end{tabular}

\section{Volumetria de neutralização}

Transferiu-se $20 \mathrm{~mL}$ de solução de $\mathrm{HCl} 0,1 \mathrm{~mol} \mathrm{~L}^{-1}$ para um béquer de $250 \mathrm{~mL}$, padronizada com bórax como padrão primário e diluiu-se para $100 \mathrm{~mL}$ com água destilada. Adicionou-se 6 gotas do extrato indicador à solução ácida. Em seguida, titulou-se com solução de $\mathrm{NaOH} \pm 0,1 \mathrm{~mol} \mathrm{~L}^{-1}$ sob constante agitação, até que houvesse mudança de cor. $\mathrm{O}$ mesmo procedimento foi realizado utilizando 3 gotas de fenolftaleína. As titulações foram realizadas em triplicata para cada indicador e a concentração média determinada para a solução de $\mathrm{NaOH}$ foi $0,1026 \mathrm{~mol} \mathrm{~L}^{-1}$.

\section{Titulação potenciométrica}

Transferiu-se $20 \mathrm{~mL}$ de solução padronizada de $\mathrm{HCl}$ 0,1 $\mathrm{mol} \mathrm{L}^{-1}$ para um béquer de $250 \mathrm{~mL}$ e diluiu-se para $100 \mathrm{~mL}$ com água destilada. Adicionou-se 6 gotas de solução de cada extrato natural e sob agitação realizou-se a titulação com $\mathrm{NaOH} 0,1 \mathrm{~mol} \mathrm{~L}^{-1}$. Anotou-se a cor e o pH do sistema após cada adição do titulante. Realizou-se o mesmo procedimento utilizando 3 gotas do indicador convencional fenolftaleína.

\section{Estudo espectrofotométrico na região do UV/visível}

Foram preparadas soluções isoladas de cada extrato em balão de $50 \mathrm{~mL}$. Para cada extrato coletou-se a seguinte alíquota da solução de indicador: para os extratos de jabuticaba, jambolão, flamboyant, repolho roxo e lobeira foram utilizados $4 \mathrm{~mL}$; para petúnia e ipê roxo, alíquotas de $3 \mathrm{~mL}$; para pata de vaca e picão, 3,6 e 1,4 mL, respectivamente. Em seguida, foram adicionadas alíquotas de solução de $\mathrm{NaOH}$ 1,0 mol L-1 em cada balão, sendo que: para jabuticaba, petúnia, pata de vaca, picão e lobeira adicionou-se alíquota de 0,2 $\mathrm{mL}$ de $\mathrm{NaOH}$ 1,0 $\mathrm{mol} \mathrm{L}^{-1}$; para jambolão, flamboyant, repolho roxo, quaresmeira e ipê roxo, alíquota de $0,1 \mathrm{~mL}$ de $\mathrm{NaOH} 1,0 \mathrm{~mol} \mathrm{~L}^{-1}$. Completou-se o volume para $50 \mathrm{~mL}$ com água destilada. A seguir, determinou-se o comprimento de onda de máxima absorbância para cada extrato em um espectrofotômetro UV/visível, modelo Ultrospec 2100 pro marca Biochrom.

\section{Determinação do $\mathbf{p K}$ ind}

Inicialmente foram preparadas soluções de cada extrato em balões de $250 \mathrm{~mL}$. Para isso, adicionou-se $20 \mathrm{~mL}$ de solução de tampão em $\mathrm{pH} 4,00$ ou 7,00 ou 8,00 ou 10,00, conforme a faixa de $\mathrm{pH}$ de transição de cor de cada extrato, juntamente com as alíquotas da solução do extrato, sendo: jabuticaba $(20,0 \mathrm{~mL}, \mathrm{pH} 7,00)$; petúnia $(15,0 \mathrm{~mL}$, $\mathrm{pH} 7,00)$; pata de vaca $(18,0 \mathrm{~mL}, \mathrm{pH} 8,00)$; picão $(7,0 \mathrm{~mL}, \mathrm{pH} 8,00)$; jambolão, repolho roxo, quaresmeira e lobeira $(20,0 \mathrm{~mL}, \mathrm{pH} 8,00)$; ipê roxo $(15,0 \mathrm{~mL}, \mathrm{pH} 8,00)$. Em seguida, completou-se o volume com água destilada. Para o extrato de flamboyant, o pH foi ajustado com solução de $\mathrm{HCl}$ e $\mathrm{NaOH} 0,01 \mathrm{~mol} \mathrm{~L}^{-1}$.

Após o preparo destas soluções, realizou-se o seguinte procedimento para cada extrato: 5 béqueres com capacidade para $50 \mathrm{~mL}$ foram numerados de 1 a 5 e para cada um foram transferidos 40 $\mathrm{mL}$ de solução descrita anteriormente. Em seguida, o $\mathrm{pH}$ em cada béquer foi ajustado de tal modo que, do béquer 1 para o béquer 5 , o $\mathrm{pH}$ fosse sendo acrescido de aproximadamente 0,30 unidades. Para o ajuste do $\mathrm{pH}$ foram usadas soluções aquosas 1,0; 0,1 e 0,01 mol $\mathrm{L}^{-1}$ de $\mathrm{NaOH}$ ou $\mathrm{HCl}$. Depois de ter o $\mathrm{pH}$ ajustado, a solução de cada béquer foi submetida ao espectrofotômetro de UV/visível para medida da absorbância. Em seguida, as soluções do béquer 1 e do béquer 5 tiveram o $\mathrm{pH}$ reajustado, de modo que a solução do béquer 1 tivesse $\mathrm{pH}$ correspondente ao mínimo de absorbância, equivalente à absorbância da forma ácida do indicador, e a solução do béquer 5 ficasse com um pH correspondente a um máximo de absorbância, equivalente à absorbância da forma básica do indicador. ${ }^{6}$

\section{Análises cromatográficas}

\section{Preparo de amostra}

De cada extrato liofilizado foi preparada uma solução a $2 \%(\mathrm{~m} / \mathrm{v})$ usando como solvente $\mathrm{HCl}$ a $0,01 \%$ (v/v), com $\mathrm{pH}$ próximo de 3,12 . Transferiu-se $1 \mathrm{~mL}$ de cada solução para tubos de ensaio de $10 \mathrm{~mL}$ de capacidade. Em cada um desses tubos foram adicionados 5,0 mL de solução de $\mathrm{HCl}$ 0,01\% (v/v). Em seguida, todos os tubos foram submetidos à centrifugação, a uma velocidade de $4000 \mathrm{rpm}$.

As amostras foram purificadas utilizando cartuchos de extração em fase sólida C18 de $500 \mathrm{mg}$ da Waters ${ }^{\mathrm{a}}$. Os cartuchos foram previamente ativados com metanol e água ultrapura. No cartucho foram aplicados 2,0 mL de solução de amostra e 2,0 mL de solução aquosa de $\mathrm{HCl} 0,01 \%$ (v/v) para eliminar compostos altamente polares. Em seguida, o corante retido na fase estacionária foi eluído com 1,0 mL de metanol e recolhido em tubo de ensaio. No tubo de ensaio foi aplicado fluxo de nitrogênio puro para total evaporação do metanol e a amostra foi diluída para $1 \mathrm{~mL}$ de solução aquosa de $\mathrm{HCl} 0,01 \%(\mathrm{v} / \mathrm{v}))^{7,8}$

Por fim, para estabelecer o comprimento de onda de máxima absorbância $\left(\lambda_{\text {máx }}\right)$, as soluções obtidas foram analisadas por espectrofotometria UV/visível, tendo como branco a solução de $\mathrm{HCl}$ $0,01 \%(\mathrm{v} / \mathrm{v})$.

\section{$H P L C / U V$-vis}

As melhores condições cromatográficas foram definidas por HPLC/UV-visível utilizando HPLC-10 ADvp Shimadzuâa ajustado 
para uma faixa espectral entre 200 e $600 \mathrm{~nm}$. No entanto, a análise de cada amostra foi realizada no comprimento de onda de máxima absorção, conforme determinado pelas análises de espectrofotometria UV/visível para cada extrato, sendo os seguintes comprimentos de ondas utilizados: jabuticaba $(510 \mathrm{~nm})$, jambolão $(520 \mathrm{~nm})$, petúnia $(546 \mathrm{~nm})$, flamboyant $(514 \mathrm{~nm})$, pata de vaca $(540 \mathrm{~nm})$, flor de picão $(362 \mathrm{~nm})$, repolho roxo $(534 \mathrm{~nm})$, quaresmeira $(544 \mathrm{~nm})$, flor de ipê roxo $(576 \mathrm{~nm})$ e flor de lobeira $(534 \mathrm{~nm})$.

A coluna cromatográfica utilizada foi a RP-18 Chromolith Merck ${ }^{\circledR}$

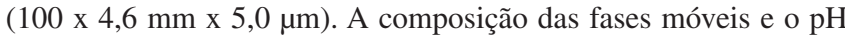
empregados na análise de cada indicador são mostrados na Tabela 3. A separação cromatográfica foi isocrática, nas seguintes condições: vazão da fase móvel - $0,4 \mathrm{~mL} \mathrm{~min}^{-1}$; tempo de corrida de $20 \mathrm{~min}$ para jabuticaba, jambolão, quaresmeira e lobeira, de 25 min para o repolho roxo, de 30 min para petúnia, flamboyant e ipê roxo, de 50 min para picão e de 70 min para pata de vaca. O volume de solução de amostra injetada foi de $20 \mu \mathrm{L}$.

Tabela 3. Composição e pH de cada fase móvel

\begin{tabular}{lcccc}
\hline & \multicolumn{3}{c}{ Composição volumétrica da fase móvel } & \\
\cline { 2 - 4 } Indicador & $\begin{array}{c}\text { Água } \\
(\%)\end{array}$ & $\begin{array}{c}\text { Acetonitrila } \\
(\%)\end{array}$ & $\begin{array}{c}\text { Ácido } \\
\text { fórmico }(\%)\end{array}$ & $\mathrm{pH}$ \\
\hline Flamboyant & 87 & 8 & 5 & 2,04 \\
\hline $\begin{array}{l}\text { Jabuticaba } \\
\text { Jambolão }\end{array}$ & 85 & 10 & 5 & 2,05 \\
$\begin{array}{l}\text { Pata de Vaca } \\
\text { Petúnia }\end{array}$ & & & & \\
$\begin{array}{l}\text { Picão } \\
\text { Repolho Roxo }\end{array}$ & 80 & 15 & 5 & 2,07 \\
$\begin{array}{l}\text { Ipê Roxo } \\
\text { Lobeira }\end{array}$ & & & & \\
\hline Quaresmeira & 70 & 25 & 5 & 2,17 \\
\hline
\end{tabular}

\section{HPLC/MS}

As análises por HPLC/MS foram realizadas em um cromatógrafo, HPLC Shimadzu AD vp, acoplado a um espectrômetro de massas Quattro LC (Micromass) e equipado com z-spray, operando em modo de eletrospray com ionização positiva (ES+). O sistema foi totalmente automatizado e controlado pelo software MASSLYNX versão 3.4 para Windows NT. A temperatura de dessolvatação (nebulização) foi $220 \mathrm{e}$ $100{ }^{\circ} \mathrm{C}$ para a fonte. A energia do capilar esteve entre 2,75 e 3,20 KV. A energia de cone foi fixada em $40 \mathrm{~V}$. O intervalo utilizado para a razão massa/carga foi de 100 a 1000 Da. As condições cromatográficas utilizadas, tais como coluna cromatográfica, fase móvel, comprimento de onda máximo $\left(\lambda_{\text {máx }}\right)$ e tempo de corrida para cada amostra, vazão da fase móvel e o volume da solução de amostra analisado foram as mesmas definidas para as análises de HPLC-UV/vis.

\section{Aplicação de extratos naturais como indicadores de reação ácido-base ${ }^{9}$}

Pesou-se 4,00 g de calcário e adicionou-se lentamente $200 \mathrm{~mL}$ de solução de $\mathrm{HCl} 0,5 \mathrm{~mol} \mathrm{~L}^{-1}$. O volume foi completado para 1000 $\mathrm{mL}$ com água destilada. Em seguida, $20 \mathrm{~mL}$ dessa solução foram transferidos para erlemmeyer de $250 \mathrm{~mL}$ e diluídos até $50 \mathrm{~mL}$ com água destilada. Adicionou-se 3 gotas de uma solução do indicador fenolftaleína e o excesso de solução de $\mathrm{HCl} 0,5 \mathrm{~mol} \mathrm{~L}^{-1}$, que não reagiu com carbonato, foi neutralizado com solução de $\mathrm{NaOH}$ 0,1068 mol L ${ }^{-1}$. Esse procedimento foi repetido substituindo as 3 gotas de fenolftaleína por 6 gotas de indicador natural. Todas as titulações foram feitas em triplicata.

\section{RESULTADOS E DISCUSSÃO}

\section{Volumetria ácido-base e titulação potenciométrica}

A Tabela 4 apresenta os resultados obtidos para a volumetria de neutralização e titulação potenciométrica utilizando os extratos de plantas como indicador. Para todas as amostras investigadas observa-se uma nítida e rápida mudança de coloração em função da variação do $\mathrm{pH}$, característica fundamental para um indicador. ${ }^{9-11}$

Observa-se que os volumes obtidos no ponto final de reação apresentam pequena variação de volume de $\mathrm{NaOH} \pm 0,1 \mathrm{~mol} \mathrm{~L}^{-1}$ consumido quando se compara com o indicador fenolftaleína. Essa variação é de $+0,3 \mathrm{~mL}$ para os extratos de flor de quaresmeira e de flor de lobeira; de $-0,1 \mathrm{~mL}$ para o extrato de flor de pata de vaca; de $+0,1 \mathrm{~mL}$ para os extratos de flor de petúnia, casca de jabuticaba e flor de ipê e para os outros extratos não houve variação. Considerando que o erro aceitável em análise química quantitativa em relação a medidas de volume usando buretas graduadas ao décimo é da ordem de $\pm 0,1$ $\mathrm{mL},{ }^{10}$ apenas os resultados obtidos com os extratos de flor de quaresmeira e de flor de lobeira estão acima do limite de erro permitido.

Outro fato interessante observado durante as titulações potenciométricas foi que, com exceção dos extratos das flores do picão e do ipê, os indicadores naturais de todas as outras espécies apresentaram diminuição da intensidade da coloração inicial à medida que o pH do meio ia se aproximando do ponto final da reação entre o ácido e a base, até deixar o sistema incolor. Em seguida, com a adição de apenas uma pequena fração de volume de solução de $\mathrm{NaOH} \pm 0,1$

Tabela 4. Resultados das titulações utilizando extratos de plantas como indicador

\begin{tabular}{|c|c|c|c|c|c|c|c|c|c|c|c|c|}
\hline Extrat & & jbtcb & $\mathrm{jbl}$ & ptn & $\mathrm{fbt}$ & $\mathrm{ptv}$ & $\mathrm{pc}$ & $\mathrm{rr}$ & qrm & ir & $\mathrm{lb}$ & fntn \\
\hline \multirow{3}{*}{$\begin{array}{l}\text { Antes do } \\
\text { ponto final }\end{array}$} & Vol. mL & 19,5 & 19,4 & 19,5 & 19,4 & 19,3 & 19,4 & 19,4 & 19,7 & 19,5 & 19,7 & 19,4 \\
\hline & $\mathrm{pH}$ & 6,27 & 5,23 & 6,80 & 5,79 & 5,85 & 6,85 & 6,40 & 6,75 & 5,58 & 6,51 & 7,25 \\
\hline & Cor & inc $^{a}$ & inc & inc & inc & inc & $\begin{array}{c}\text { amarelo } \\
\text { claro }\end{array}$ & inc & inc & roxo & inc & inc \\
\hline \multirow{3}{*}{ Ponto final } & Vol. mL & 19,6 & 19,5 & 19,6 & 19,5 & 19,4 & 19,5 & 19,5 & 19,8 & 19,6 & 19,8 & 19,5 \\
\hline & $\mathrm{pH}$ & 8,00 & 6,80 & 7,63 & 8,11 & 7,50 & 8,86 & 7,97 & 7,62 & 6,11 & 7,03 & 9,36 \\
\hline & Cor & $\begin{array}{l}\text { verde } \\
\text { claro }\end{array}$ & $\begin{array}{l}\text { verde } \\
\text { claro }\end{array}$ & $\begin{array}{l}\text { verde } \\
\text { claro }\end{array}$ & $\begin{array}{l}\text { verde } \\
\text { claro }\end{array}$ & $\begin{array}{l}\text { verde } \\
\text { claro }\end{array}$ & $\begin{array}{c}\text { amarelo } \\
\text { alaranjado }\end{array}$ & $\begin{array}{l}\text { verde } \\
\text { claro }\end{array}$ & $\begin{array}{l}\text { verde } \\
\text { claro }\end{array}$ & azul & $\begin{array}{l}\text { verde } \\
\text { claro }\end{array}$ & $\begin{array}{l}\text { rosa } \\
\text { claro }\end{array}$ \\
\hline \multirow{2}{*}{$\begin{array}{l}\text { Depois do } \\
\text { ponto final }\end{array}$} & Vol. mL & 19,7 & 19,6 & 19,7 & 19,6 & 19,5 & 19,6 & 19,6 & 19,9 & 19,7 & 19,9 & 19,6 \\
\hline & cor & verde & verde & verde & $\begin{array}{c}\text { verde } \\
\text { amarelado }\end{array}$ & verde & $\begin{array}{c}\text { amarelo } \\
\text { alaranjado }\end{array}$ & verde & verde & $\begin{array}{c}\text { azul } \\
\text { esverdeado }\end{array}$ & verde & rosa \\
\hline \multicolumn{2}{|c|}{ Intervalo de $\mathrm{pH}$} & 1,73 & 1,57 & 0,83 & 2,32 & 1,62 & 2,01 & 1,57 & 0,91 & 0,53 & 0,52 & 2,11 \\
\hline
\end{tabular}

a=incolor; jbtcb=jabuticaba; jbl=jambolão; $p t n=$ petunia; $f b t=$ flamboyant; $p t v=$ pata de vaca; pc=picão; rr=repolho roxo; qrm=quaresmeira; ir=ipê roxo; lb=lobeira; fntn=fenolftaleína. 
mol L ${ }^{-1}$, o sistema assumia a tonalidade verde clara, sugerindo excesso da forma alcalina em relação à forma ácida do indicador, conforme apresentado na Tabela 5. Depois que o ponto final da reação era atingido e a adição da solução básica continuava, a coloração do sistema ia se tornando mais intensa, passando do verde claro para verde, do verde para o verde amarelado e deste para o amarelo.

Tabela 5. Ilustração da variação de cor dos extratos das espécies de plantas investigadas em função do $\mathrm{pH}$

\begin{tabular}{|c|c|c|c|c|c|c|c|c|c|c|c|}
\hline \multirow{2}{*}{ Indicador } & \multicolumn{11}{|c|}{ Cor em função do pH } \\
\hline & 2 & 3 & 4 & 5 & 6 & 7 & 8 & 9 & 10 & 11 & 12 \\
\hline \multicolumn{12}{|l|}{ Jabuticaba } \\
\hline \multicolumn{12}{|l|}{ Jambolão } \\
\hline \multicolumn{12}{|l|}{ Petúnia } \\
\hline \multicolumn{12}{|l|}{ Flamboyant } \\
\hline \multicolumn{12}{|l|}{ Pata de Vaca } \\
\hline \multicolumn{12}{|l|}{ Picão } \\
\hline \multicolumn{12}{|l|}{ Repolho Roxo } \\
\hline \multicolumn{12}{|l|}{ Quaresmeira } \\
\hline \multicolumn{12}{|l|}{ Ipê Roxo } \\
\hline \multicolumn{12}{|l|}{ Lobeira } \\
\hline Fenolftaleína & & & & & & & & & & & \\
\hline
\end{tabular}

Esta mudança de coloração em função da variação do $\mathrm{pH}$ da solução contendo antocianinas está associada a alterações estruturais desses compostos, como mostrado na Figura 1S, material suplementar. Quando o pH for entre 1 e 2 unidades, a solução indicadora apresentará coloração geralmente vermelha, devido à elevada concentração da forma estrutural do cátion flavilium. Em $2<\mathrm{pH}<6$ a antocianina se encontra na forma de carbinol e a coloração vermelha diminui de intensidade. À medida que o pH aumenta, a intensidade da coloração vermelha diminui até a solução ficar incolor. Entre pH 6,6 e 8, a solução assume uma coloração que varia do violeta ao azul, devido à presença da forma estrutural anidrobase. Com a elevação do $\mathrm{pH}$, a anidrobase produzida vai sofrendo ionização e, à medida que esta ionização aumenta, a solução primeiro assume uma coloração azul-esverdeada entre $\mathrm{pH} 8$ e 10, depois passa do verde ao verde-amarelado entre pH 10 e 12. Acima de pH 12, a solução se torna amarela ocorrendo a abertura do anel benzopirilium, dando origem a estruturas chamadas chalconas. ${ }^{12}$

Para os indicadores naturais aqui estudados, este comportamento também é verificado, de modo que um pouco antes do ponto final da titulação, todos eles conferiram coloração à solução. Com a adição de apenas $0,1 \mathrm{~mL}$ da solução de $\mathrm{NaOH} \pm 0,1 \mathrm{~mol} \mathrm{~L}^{-1}$, a coloração do sistema mudou de maneira considerável. Os intervalos de $\mathrm{pH}$ correspondentes à estimativa da zona de transição de cor de cada um dos extratos naturais estão contidos na Tabela 5. Observa-se que os indicadores naturais avaliados que apresentaram intervalo de $\mathrm{pH}$ maior que 2 unidades para mudança de coloração foram aqueles obtidos a partir dos extratos de pétalas de flamboyant e picão; e os que apresentaram intervalo de $\mathrm{pH}$ para transição de cor menor que uma unidade de $\mathrm{pH}$ foram aqueles obtidos a partir de extratos de pétalas de petúnia, quaresmeira, ipê roxo e lobeira. Todavia, todos proporcionaram boa percepção visual do ponto final de titulação.

Outro aspecto a ser abordado relaciona-se com o tipo de volumetria ácido-base no qual o indicador pode ser utilizado. Quando um indicador possui intervalo de $\mathrm{pH}$ para mudança de coloração localizado na região ligeiramente ácida da escala de $\mathrm{pH}(5<\mathrm{pH}<7)$, o uso desse indicador é recomendado nas titulações de base fraca por ácido forte, pois o ponto final nesse tipo de titulação ocorre em $\mathrm{pH}$ ligeiramente ácido; quando o indicador possui o intervalo de $\mathrm{pH}$ para a mudança de coloração localizado na região ligeiramente básica $(7<\mathrm{pH}<9)$, o uso desse indicador é recomendado nas titulações de ácido fraco por base forte, pois neste caso, o ponto final da titulação acontece em um pH ligeiramente alcalino.

Verifica-se também que, quanto à localização do intervalo de $\mathrm{pH}$ para a transição de cor, existem três grupos distintos de indicadores. No primeiro, numa faixa de $\mathrm{pH}$ ligeiramente ácida, encontram-se os indicadores naturais obtidos da casca do jambolão $(5,23<\mathrm{pH}<6,80) \mathrm{e}$ das pétalas da lobeira $(6,51<\mathrm{pH}<7,03)$ e, desse modo, podem substituir alguns indicadores convencionais, tais como o púrpura de bromocresol $(5,2<\mathrm{pH}<6,8)$ e o vermelho de clorofenol $(5,0<\mathrm{pH}<6,6)$. Já o indicador obtido do extrato de pétalas de picão apresentou intervalo de pH entre 6,85 e 8,86, ou seja, o ponto final da titulação está localizado em uma região ligeiramente básica da escala de $\mathrm{pH}$ e, sendo assim, pode ser usado como substituto para diversos indicadores convencionais como, por exemplo, ácido rosólico $(6,8<\mathrm{pH}<8,2)$, alaranjado de propil-alfa-naftol $(7,4<\mathrm{pH}<8,9)$, alfa-naftoltaleína $(7,3<\mathrm{pH}<8,7)$, amarelo-brilhante $(7,4<\mathrm{pH}<8,5)$, benzeno de cresol $(7,2<\mathrm{pH}<8,5)$, curcumina amarela $(7,4<\mathrm{pH}<8,6)$, fenolftaleína $(8,3<\mathrm{pH}<9,8)$, tropeolina $(7,6<\mathrm{pH}<8,9)$ e vermelho de cresol $(7,2<\mathrm{pH}<8,8)$. No terceiro grupo encontram-se os demais indicadores - jabuticaba, petúnia, flamboyant, pata de vaca, repolho roxo, quaresmeira e ipê roxo - que possuem um intervalo de $\mathrm{pH}$ para mudança de coloração iniciando em $\mathrm{pH}$ ácido e terminando em $\mathrm{pH}$ básico $(5,80<\mathrm{pH}<8,11)$. Em decorrência disso, esses indicadores podem substituir alguns indicadores convencionais, tais como, ácido rosólico $(6,8<\mathrm{pH}<8,2)$, azul de bromotimol $(6,0<\mathrm{pH}<7,6)$, metanitrofenol $(6,8<\mathrm{pH}<8,4)$, pinacromo $(5,8<\mathrm{pH}<7,8)$ e vermelho neutro $(6,8<\mathrm{pH}<8,0) .{ }^{10}$

Dessa forma, todas as amostras apresentaram diversas variações de cor ao longo da escala de $\mathrm{pH}$, mas apenas as flores de picão e ipê roxo apresentaram mudança de coloração acompanhada de variação brusca de $\mathrm{pH}$, um comportamento similar ao indicador fenolftaleína, como mostrado na Tabela 5 .

\section{Estudo espectrofotométrico para determinação do $\mathbf{p K}_{\text {in }}$}

Os indicadores naturais estudados desenvolveram várias colorações ao longo da escala de $\mathrm{pH}$. Por isso, no estudo espectrofotométrico desses indicadores foi necessário escolher uma região desta escala onde ocorre mudança nítida e rápida de coloração associada à variação brusca de $\mathrm{pH}$, que ocorre próximo de $\mathrm{pH} 7$ por ser uma titulação de ácido forte por base forte. Assim, a Tabela 6 apresenta a absorbância em diferentes valores de $\mathrm{pH}$ para os diversos indicadores, os quais foram utilizados para o cálculo do $\mathrm{pK}_{\mathrm{in}}$ dos indicadores naturais utilizando a equação $p K i n=p H+\log \left(\frac{A-A_{I n}-}{A_{H I n}-A}\right)$, deduzida a partir da combinação da Equação de Lambert-Beer e da lei da ação das massas para o equilíbrio $\mathrm{HIn} \rightleftharpoons \mathrm{H}^{+}+\mathrm{In}^{-}$. Os dados foram comparados com dois indicadores convencionais para se verificar a aplicabilidade do método utilizado.

Uma estimativa do intervalo de $\mathrm{pH}$ com transição de cor para cada indicador pode ser dada por $\mathrm{pH}=\mathrm{pK}_{\mathrm{in}} \pm 1$, conforme apresentado na Tabela 6. Na verdade, o cálculo do intervalo de $\mathrm{pH}$ para transição de cor para um indicador ácido-base usando esta equação é aproximado e muitas vezes não coincide com os valores encontrados na literatura. Isto ocorre porque a mudança de coloração depende da natureza intrínseca de cada indicador e também da capacidade visual de cada observador. ${ }^{9}$ É importante observar que os valores obtidos de $\mathrm{pK}_{\text {in }}$ e da faixa de $\mathrm{pH}$ com transição de cor para a fenolftaleína e o azul de bromofenol são semelhantes aos descritos em literatura, ${ }^{6,9}$ o que sugere a aplicabilidade do método também aos indicadores naturais. 
Tabela 6. Dados utilizados na determinação do pKin para cada extrato indicador

\begin{tabular}{|c|c|c|c|c|c|c|c|c|c|c|c|c|}
\hline Extrato & jbtcb & $\mathrm{jbl}$ & Ptn & $\mathrm{fbt}$ & ptv & $\mathrm{pc}$ & $\mathrm{rr}$ & qrm & ir & $\mathrm{lb}$ & fntn & abfn \\
\hline$\underline{\lambda}_{\text {max }}(\mathrm{nm})$ & 572 & 600 & 610 & 410 & 380 & 484 & 604 & 640 & 382 & 378 & 552 & 592 \\
\hline \multirow{7}{*}{$\mathrm{pH}$} & 6,99 & 6,81 & 7,32 & 7,21 & 7,30 & 7,60 & 6,89 & 6,99 & 7,35 & 7,02 & 8,77 & 3,42 \\
\hline & 7,29 & 7,11 & 7,61 & 7,50 & 7,59 & 7,90 & 7,20 & 7,30 & 7,67 & 7,33 & 9,09 & 3,72 \\
\hline & 7,59 & 7,42 & 7,90 & 7,79 & 7,89 & 8,18 & 7,49 & 7,60 & 8,00 & 7,62 & 9,38 & 4,04 \\
\hline & 7,88 & 7,71 & 8,20 & 8,08 & 8,17 & 8,50 & 7,81 & 7,88 & 8,28 & 7,90 & 9,70 & 4,32 \\
\hline & 8,17 & 7,99 & 8,50 & 8,39 & 8,46 & 8,80 & 8,10 & 8,19 & 8,58 & 8,21 & 10,03 & 4,61 \\
\hline & 2,16 & 2,04 & 2,00 & 4,11 & 2,02 & 2,03 & 4,09 & 2,00 & 2,01 & 2,82 & 2,01 & 2,00 \\
\hline & 10,63 & 8,83 & 11,72 & 9,68 & 12,02 & 12,02 & 9,64 & 11,98 & 9,86 & 9,62 & 12,03 & 12,00 \\
\hline \multirow{7}{*}{ Absorbância } & 0,332 & 0,322 & 0,375 & 0,339 & 0,362 & 0,279 & 0,345 & 0,282 & 0,188 & 0,292 & 0,052 & 0,135 \\
\hline & 0,356 & 0,352 & 0,405 & 0,390 & 0,421 & 0,360 & 0,425 & 0,368 & 0,265 & 0,338 & 0,113 & 0,224 \\
\hline & 0,420 & 0,445 & 0,441 & 0,442 & 0,493 & 0,428 & 0,535 & 0,440 & 0,384 & 0,392 & 0,216 & 0,355 \\
\hline & 0,460 & 0,545 & 0,489 & 0,504 & 0,554 & 0,518 & 0,635 & 0,480 & 0,483 & 0,453 & 0,400 & 0,465 \\
\hline & 0,508 & 0,672 & 0,543 & 0,567 & 0,630 & 0,605 & 0,675 & 0,504 & 0,585 & 0,518 & 0,571 & 0,566 \\
\hline & $0,112^{\mathrm{a}}$ & $0,125^{\mathrm{a}}$ & $0,249^{a}$ & $0,086^{\mathrm{a}}$ & $0,200^{\mathrm{a}}$ & $0,104^{\mathrm{a}}$ & $0,095^{\mathrm{a}}$ & $0,040^{\mathrm{a}}$ & $0,089^{\mathrm{a}}$ & $0,163^{\mathrm{a}}$ & $0,007^{\mathrm{a}}$ & $0,010^{\mathrm{a}}$ \\
\hline & $0,688^{\mathrm{b}}$ & $0,842^{\mathrm{b}}$ & $0,705^{\mathrm{b}}$ & $0,699^{\mathrm{b}}$ & $0,842^{\mathrm{b}}$ & $0,902^{\mathrm{b}}$ & $0,750^{\mathrm{b}}$ & $0,880^{\mathrm{b}}$ & $0,808^{\mathrm{b}}$ & $0,703^{\mathrm{b}}$ & $0,790^{\mathrm{b}}$ & $0,753^{\mathrm{b}}$ \\
\hline \multirow{5}{*}{$\log \left(\frac{A-A_{I^{-}}}{A_{H i n}-A}\right)$} & 0,21 & 0,42 & 0,42 & 0,15 & 0,47 & 0,55 & 0,19 & 0,42 & 0,80 & 0,50 & 1,21 & 0,69 \\
\hline & 0,13 & 0,33 & 0,28 & 0,01 & 0,28 & 0,32 & $-0,03$ & 0,19 & 0,49 & 0,32 & 0,81 & 0,39 \\
\hline & $-0,06$ & 0,09 & 0,14 & $-0,14$ & 0,08 & 0,16 & $-0,35$ & 0,04 & 0,16 & 0,13 & 0,44 & 0,06 \\
\hline & $-0,18$ & $-0,15$ & $-0,05$ & $-0,33$ & $-0,09$ & $-0,03$ & $-0,78$ & $-0,04$ & $-0,08$ & $-0,06$ & 0,00 & $-0,20$ \\
\hline & $-0,34$ & $-0,51$ & $-0,26$ & $-0,56$ & $-0,31$ & $-0,23$ & $-1,02$ & $-0,09$ & $-0,35$ & $-0,28$ & $-0,41$ & $-0,47$ \\
\hline \multirow{5}{*}{ pKin } & 7,20 & 7,23 & 7,74 & 7,36 & 7,77 & 8,15 & 7,08 & 7,41 & 8,15 & 7,52 & 9,98 & 4,11 \\
\hline & 7,42 & 7,44 & 7,89 & 7,49 & 7,87 & 8,22 & 7,17 & 7,49 & 8,16 & 7,65 & 9,89 & 4,11 \\
\hline & 7,53 & 7,51 & 8,04 & 7,65 & 7,97 & 8,34 & 7,14 & 7,64 & 8,16 & 7,75 & 9,82 & 4,10 \\
\hline & 7,70 & 7,56 & 8,15 & 7,75 & 8,08 & 8,47 & 7,03 & 7,84 & 8,20 & 7,84 & 9,70 & 4,12 \\
\hline & 7,83 & 7,48 & 8,24 & 7,83 & 8,15 & 8,57 & 7,08 & 8,10 & 8,23 & 7,93 & 9,62 & 4,13 \\
\hline $\mathrm{pK}_{\text {in }}$ médio & 7,54 & 7,44 & 8,01 & 7,62 & 7,97 & 8,35 & 7,10 & 7,69 & 8,18 & 7,74 & 9,80 & 4,11 \\
\hline desvio padrão & 0,34 & 0,21 & 0,27 & 0,26 & 0,20 & 0,22 & 0,07 & 0,41 & 0,05 & 0,22 & 0,18 & 0,02 \\
\hline
\end{tabular}

Intervalo de $\mathrm{pH}$ para

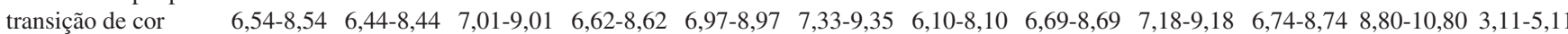
$\left(\mathrm{pH}=\mathrm{pK}_{\text {in }} \pm 1\right)$

$\mathrm{a}=\mathrm{A}_{\mathrm{Hin}} ; \mathrm{b}=\mathrm{A}_{\mathrm{HIn-}} ; \mathrm{jbtcb}=$ jabuticaba; jbl=jambolão; $\mathrm{ptn}=$ petunia; fbt=flamboyant; $\mathrm{ptv}=$ pata de vaca; $\mathrm{pc}=\mathrm{picão}$; $\mathrm{rr}=\mathrm{repolho}$ roxo; qrm=quaresmeira; ir=ipê roxo; $\mathrm{lb}=$ lobeira; fntn=fenolftaleína; azul de bromofenol

\section{Caracterização de antocianinas por HPLC/MS}

Dependendo dos procedimentos de extração e de purificação utilizados para obtenção de pigmentos de espécies vegetais pode-se obter isoladamente agliconas, antocianinas ou uma mistura das duas com predominância de antocianinas. Se na etapa de extração for usado como solvente extrator uma solução etanólica de $\mathrm{HCl}$ a $1 \%$ (v/v), a hidrólise completa dos açúcares desses compostos ocorrerá em $1 \mathrm{~h}$, a uma temperatura de $60{ }^{\circ} \mathrm{C}$. ${ }^{13}$ Portanto, os dois fatores preponderantes e que devem ser controlados de forma simultânea para que aconteça a hidrólise completa dos açúcares são temperatura e pH ácido. Se ocorrer hidrólise total serão detectadas apenas as agliconas. Todavia, se estes dois fatores, $\mathrm{pH}$ ácido (menor que 1,0) e temperatura, forem usados em momentos distintos, haverá hidrólise parcial das antocianinas e, desse modo, serão detectadas antocianinas e suas respectivas agliconas.

O procedimento de extração adotado proporcionou a hidrólise parcial dos açúcares, de modo que foram detectadas antocianinas e agliconas por HPLC/MS. A extração etanólica por $2 \mathrm{~h}$, à temperatura ambiente, sem a utilização de $\mathrm{HCl}$ a $1 \%(\mathrm{pH}<1)$, rotoevaporação a uma temperatura inferior a $60{ }^{\circ} \mathrm{C}$ e utilização de $\mathrm{HCl}$ a $0,01 \%$ (v/v) $(\mathrm{pH} \pm 3)$ sem aquecimento na extração em fase sólida minimizaram a hidrólise dos açúcares. A Figura 2 apresenta o cromatograma de íons totais obtido para o extrato de flor de picão e a Tabela 8 mostra as principais antocianinas identificadas para as demais plantas estudadas. A simbologia e os fragmentos característicos para agliconas, açúcares e ácidos são apresentados na Tabela 7.
A identificação das antocianinas foi realizada inicialmente com o auxílio dos espectros de massas correspondentes à varredura dos fragmentos das agliconas isoladas. ${ }^{14-18}$ Posteriormente, realizou-se a varredura dos fragmentos correspondentes à associação das agliconas com açúcares. Por último, foi realizada a varredura das massas características dos ácidos normalmente encontrados nessas amostras. Para os ácidos com massa molecular menor que $100 \mathrm{Da}$, o monitoramento envolveu também a varredura das massas correspondentes à associação desses ácidos com os açúcares e com as agliconas presentes. Um fato interessante é a provável presença da aglicona tricetidinina somente no extrato de picão, visto que apenas este extrato apresentou mudança brusca de $\mathrm{pH}$ concomitante à mudança de coloração. As antocianidinas encontradas nesta pesquisa estão de acordo com dados apresentados em estudos anteriores para as seguintes plantas: petúnia, ${ }^{19,20}$ jabuticaba, ${ }^{21}$ jambolão, ${ }^{22}$ repolho roxo, ${ }^{23,24}$ flamboyant e pata de vaca. ${ }^{25,26}$ Observouse que não é possível estimar a faixa de viragem de $\mathrm{pH}$ com base na simples avaliação dos tipos de agliconas preponderantes nos extratos vegetais, já que, por exemplo, apesar de jabuticaba e lobeira - que apresentam preponderantemente as agliconas cianidina e delfinidina - apresentarem pH de viragem de 6,5 a 8,5; jambolão e petúnia - que apresentam preponderantemente a aglicona malvidina - apresentarem diferentes de $\mathrm{pH}$ de viragem. Isto significa que a faixa de $\mathrm{pH}$ de viragem não depende somente do tipo de aglicona presente, mas de toda composição de antocianinas das amostras.

Com relação à possibilidade de interferência quanto à qualidade ou concentração das antocianinas no ponto final da titulação, 


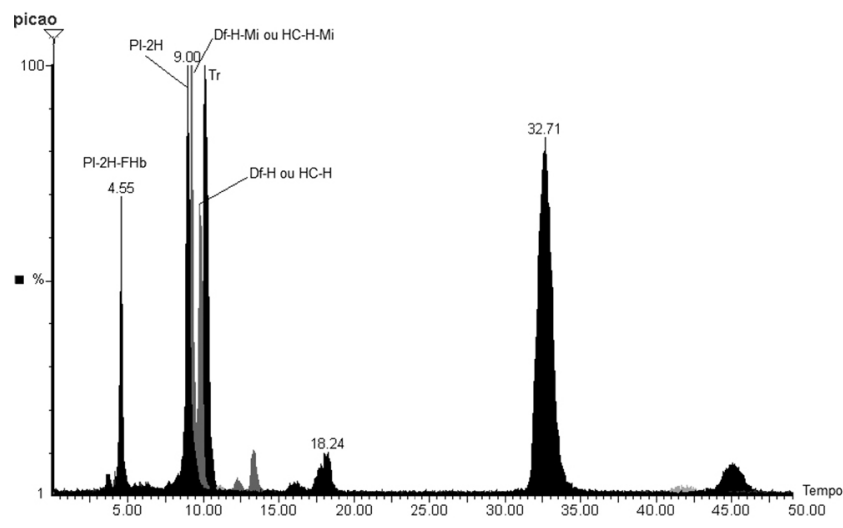

Figura 2. Cromatogramas de íns totais para as antocianinas presentes nos extratos de picão. As abreviações representam as associações das antocianinas com açúcares e ácidos (Tabela 7) verifica-se que a variabilidade natural não é tão expressiva, pois, quando se trata de plantas de uma mesma espécie parece não haver diferenças significativas na composição em antocianinas, tendo em vista que em outros trabalhos nos quais foram estudadas as mesmas plantas e os mesmos tecidos que os do presente estudo, coletadas em outros países com características de clima e relevo bem diferentes do Brasil, foram encontradas as mesmas agliconas aqui determinadas. ${ }^{19-26}$

\section{Aplicação dos indicadores naturais}

Os indicadores naturais foram aplicados na determinação indireta de carbonato em amostra de calcário, conforme apresenta a Tabela 1S, material suplementar. Também foram utilizados como parâmetros de comparação a titulação potenciométrica e o indicador fenolftaleína. Assim, os resultados demonstram que três dos indicadores naturais, extratos de jambolão, repolho roxo e ipê roxo, apresentaram o mesmo resultado obtido usando fenolftaleína.

Tabela 7. Simbologia e fragmentos característicos para agliconas, açúcares e ácidos

\begin{tabular}{|c|c|c|c|c|c|}
\hline Agliconas & $m / z$ & Açúcares & $m / z$ & Ácidos & $m / z$ \\
\hline Pelargonidina (Pl) & 271,0 & Pentose $(\mathrm{P})$ & 132,0 & Acético (A) & 42,0 \\
\hline Cianidina (Ci) & 287,0 & Hexose $(\mathrm{H})$ & 162,2 & Propiônico (Pr) & 56,1 \\
\hline Tricetidinina (Tr) & 287,0 & Ramnose (Ra) & 164,2 & Oxálico $(\mathrm{O})$ & 72,1 \\
\hline Peonidina (Po) & 301,0 & Rutinose (Ru) & 308,0 & Malônico (Mo) & 86,1 \\
\hline Delfinidina (Df) & 303,0 & & & Meleico (Me) & 98,1 \\
\hline 6-Hidroxicianidina $(\mathrm{Hc})$ & 303,0 & & & Succínico (Su) & 100,1 \\
\hline Petunidina $(\mathrm{Pt})$ & 317,0 & & & Benzoico (Bz) & 104,1 \\
\hline \multirow[t]{8}{*}{ Malvidina (Ma) } & 331,0 & & & Málico $(\mathrm{Mi})$ & 116,1 \\
\hline & & & & p-Hidroxibenzoico $(\mathrm{Hb})$ & 120,1 \\
\hline & & & & Cinâmico $(\mathrm{Cy})$ & 130,2 \\
\hline & & & & $p$-Cumárico $(\mathrm{Cu})$ & 146,2 \\
\hline & & & & Gálico $(\mathrm{G})$ & 152,1 \\
\hline & & & & Cafeico $(\mathrm{Cc})$ & 162,2 \\
\hline & & & & Ferúlico (F) & 176,2 \\
\hline & & & & Sinápico (Sp) & 206,0 \\
\hline
\end{tabular}

Tabela 8. Principais antocianinas identificadas nos extratos das plantas avaliadas. As abreviações representam as associações das antocianinas com açúcares e ácidos (Tabela 7)

Antocianinas

Tempo de eluição e fragmento $(\mathrm{min} ; \mathrm{m} / \mathrm{z})$

\begin{tabular}{|c|c|c|c|c|c|c|c|c|}
\hline \multicolumn{9}{|c|}{ Planta } \\
\hline Jabuticaba & Jambolão & Pata de vaca & Petúnia & Repolho roxo & Ipê roxo & Lobeira & Flamboyant & Quaresmeira \\
\hline $\begin{array}{c}\text { Df-H } \\
(5,92 ; 465,2) \\
\text { Df-Ra } \\
(5,92 ; 467,2) \\
\text { Ci-H } \\
(7,89 ; 449,2) \\
\text { Ci-Ra } \\
(7,89 ; 451,2)\end{array}$ & $\begin{array}{c}\text { Df-2H } \\
(4,47 ; 627,4) \\
\text { Ci-2H/ } \\
\text { Ci-H-Cc } \\
(5,15 ; 611,4) \\
\text { Pt- } 2 \mathrm{H} \\
(5,58 ; 641,4) \\
\mathrm{Ma}-2 \mathrm{H} \\
(8,06 ; 655,4) \\
\mathrm{Ma}-\mathrm{H}-\mathrm{Cu} \\
(8,32 ; 639,4)\end{array}$ & $\begin{array}{c}\text { Pl-3H-GBz } \\
(3,78 ; 1013,8) \\
\text { Df-3H-Sp } \\
(3,95 ; 995,6) \\
\text { Ci-3H-G } \\
(4,21 ; 925,7) \\
\text { Ma-2H-Cu } \\
(4,47 ; 931,8) \\
\text { Pl-HRa-FHb } \\
(11,48 ; 893,7) \\
\text { Po-H-Ra } \\
(14,82 ; 627,4) \\
\text { Ci-Ru } \\
(15,42 ; 595,2) \\
\text { Ci-H } \\
(17,13 ; 449,2) \\
\text { Ma-H } \\
(18,67 ; 493,2)\end{array}$ & $\begin{array}{c}\text { Df-3H-FccCu } \\
(3,95 ; 1274,2) \\
\text { Ci-3H-CcCuMi } \\
(4,04 ; 1198,1) \\
\mathrm{Ma}-3 \mathrm{H}-\mathrm{CcCu} \\
(4,12 ; 1126,0) \\
\mathrm{Ma}-2 \mathrm{H}-\mathrm{Gmi} \\
(4,72 ; 923,6) \\
\text { Df-3H-Su } \\
(5,75 ; 889,7) \\
\text { Df-2H-Cu } \\
(6,69 ; 773,6) \\
\mathrm{Ci}-2 \mathrm{H}-\mathrm{Mi} \\
(7,29 ; 727,5) \\
\mathrm{Ma}-2 \mathrm{H}-\mathrm{Me} \\
(8,06 ; 753,5) \\
\mathrm{Ma}-2 \mathrm{H} \\
(12,85 ; 655,4)\end{array}$ & $\begin{array}{c}\text { Ci-3H-GBzCy } \\
(3,69 ; 1160,0) \\
\text { Ci-3H-CuF } \\
(4,04 ; 1096,0) \\
\text { Ci-Ru-H } \\
(10,80 ; 757,4) \\
\text { Ci-Ra-G } \\
(11,14 ; 603,3) \\
\text { Ci-H-Me } \\
(11,40 ; 547,3)\end{array}$ & $\begin{array}{c}\text { Df-3H-GccSu } \\
(3,87 ; 1204,0) \\
\text { Df-3H-SpCc } \\
(4,12 ; 1157,8) \\
\text { Ma-RuH-SpCc } \\
(4,12 ; 1169,6) \\
\text { Df-3H } \\
(6,60 ; 789,6) \\
\text { Df-HP-MeO } \\
(8,49 ; 767,4) \\
\text { Ci-Ru-Cc } \\
(9,94 ; 757,4) \\
\text { Ci-H } \\
(13,02 ; 449,2) \\
\text { Pl-H } \\
(16,96 ; 433,2)\end{array}$ & $\begin{array}{c}\text { Df-Ru-H-F-Cc } \\
(5,66 ; 1111,8) \\
\text { Pt-Ru-H-Cu } \\
(6,01 ; 933,6) \\
\text { Ci-Ru-H-Ra } \\
(6,95 ; 921,6) \\
\text { Df-Ru-H } \\
(8,06 ; 773,4) \\
\text { Pt-Ru-H } \\
(8,32 ; 787,4) \\
\text { Df-Ru-Hb } \\
(8,40 ; 731,3) \\
\text { Pt-H-G } \\
(8,57 ; 631,3) \\
\text { Ci-Ru-H } \\
(10,63 ; 595,4) \\
\text { Ma-H } \\
(12,34 ; 493,2) \\
\text { Ci-H } \\
(12,77 ; 449,2) \\
\text { Pt-H } \\
(14,73 ; 479,2)\end{array}$ & $\begin{array}{c}\text { Pl-RuH-SpMi } \\
(4,21 ; 1063,5) \\
\text { Ci-RuH-HbSu } \\
(4,55 ; 997,6) \\
\text { Pl-RuH-Cu } \\
(5,32 ; 887,6) \\
\text { Pl-RuP-Cc } \\
(7,80 ; 873,3) \\
\text { Df-RuH } \\
(8,83 ; 773,3) \\
\text { Df-RuP } \\
(10,03 ; 743,3) \\
\text { Df-Ru } \\
(11,40 ; 611,2) \\
\text { Pl-Ra-F } \\
(11,82 ; 611,4) \\
\text { Pt-H } \\
(15,68 ; 479,2)\end{array}$ & $\begin{array}{c}\text { Df-3H-F } \\
(3,78 ; 965,8) \\
\text { Df-3H-Hb } \\
(4,04 ; 909,7) \\
\text { Df-Ru-H-Pr ou } \\
\text { Ci-Ru-H-O } \\
(4,55 ; 829,5) \\
\text { Ci-3H } \\
(5,15 ; 773,6) \\
\text { Ma-3H } \\
(5,32 ; 817,6) \\
\text { Ma-Ru-PA } \\
(5,49 ; 813,2) \\
\text { Ci-2H } \\
(6,01 ; 611,4)\end{array}$ \\
\hline
\end{tabular}


Com relação à titulação potenciométrica, os indicadores que apresentaram os melhores resultados foram aqueles obtidos de extratos de picão e de lobeira, e o que apresentou maior erro foi o extrato de jabuticaba. Desta maneira, considera-se que todos os indicadores naturais estudados podem ser aplicados a esta e outras determinações quantitativas em volumetria ácido-base, desde que sejam consideradas as características de intervalo de $\mathrm{pH}$ para a transição de cor e a estabilidade química de alguns dos extratos, notadamente aqueles preparados a partir de frutos.

\section{CONCLUSÕES}

As espécies de plantas investigadas possuem propriedades indicadoras em potencial, representando, portanto, uma alternativa de uso para alguns dos indicadores convencionais tradicionalmente utilizados. Dentre as espécies de plantas estudadas apenas a pétala de picão apresentou antocianidinas mais raras, tal como a tricetidinina, e também mostrou mudança brusca de coloração em função do $\mathrm{pH}$. Assim, o picão apresentou excelente precisão e exatidão em aplicações como indicador em titulações ácido-base.

\section{MATERIAL SUPLEMENTAR}

O material suplementar encontra-se disponível em http//quimicanova.sbq.org.br, em arquivo pdf e com acesso livre.

\section{AGRADECIMENTOS}

Ao MCT, FINEP, FUNAPE e CNPq pelo suporte financeiro, ao CNPq pela bolsa de produtividade do Prof. N. R. Antoniosi Filho (Processo 309832/2010-1).

\section{REFERÊNCIAS}

1. Gross, J.; Pigments in Fruits, Academic Press: London, 1987.

2. Vergara, C.; von Baer, D.; Hermosín, R. A.; Hitschfeld, M. A.; Castillo, N.; Mardones, C.; J. Chil. Chem. Soc. 2009, 54, 194.

3. Ikan, R.; Natural Products - A Laboratory Guide, $2^{\text {nd }}$ ed., Academic Press: New York, 1991.

4. Terci, D. B. L.; Rossi, A. V.; Quim. Nova 2002, 25, 684.
5. Vizeu, M. D.; Guimarães, P. I. C.; Merçon, F.; Quim. Nova na Escola 2003, $\mathrm{n}^{\circ} 17,27$.

6. Patterson, G. S.; J. Chem. Educ.1999, 76, 395.

7. Giusti, M. M.; Wrolstad, R. E.; J. Food Sci. 1996, 61, 322.

8. Goiffon, J. P.; Mouly, P. P.; Gaydou, E. M.; Anal. Chem. Acta 1999, 382, 39.

9. Vogel, A. I.; Análise química quantitativa, LTC Ed: Rio de Janeiro, 1992.

10. Brady, E. J.; Humiston, E. G.; Química Geral, Livros Técnicos e Científicos: Rio de Janeiro, 1981.

11. Silva, R. R.; Vocchi, N.; Rocha-Filho, R. C.; Introdução à Química Experimental, Hill: São Paulo, 1990.

12. Brouillard, R.; Iacobucci, G. A.; Sweeny, J. G.; J. Am. Chem. Soc. 1982, 104,7585

13. Harbone, J. B.; Phytochemical methods - a guide to modern techniques of plant analysis, Chapman and Hall: London, 1973.

14. Schütz, K.; Persike, M.; Carle, R.; Schieber, A.; Anal. Bioanal. Chem. 2006, 384, 1511.

15. Oh, Y. S.; Lee, J. H.; Yoon, S. H.; Oh, C. H.; Choi, D. S.; Choe, E.; Jung, M. Y.; J. Food Sci. 2008, 73, C378.

16. Kelebek, H.; Canbas, A.; Selli, S.; Chromatographia 2007, 66, 207.

17. Qingguo, T.; Giusti, M. M.; Stoner, G. D.; Schwartz, S. J.; Food Chem. 2006, 94, 465

18. Março, P. H.; Poppi, R. J.; Scarminio, I. S.; Quim. Nova 2008, 31, 1218.

19. Gerats, A. G. M.; Farçy, E.; Wallroth, M.; Groot, S. P. G.; Schram, A.; Genetics 1984, 106, 501.

20. Fukui, Y.; Kusumi, T.; Yoshida, K.; Kondo, T.; Matsuda C.; Nomoto, K.; Phytochemistry 1998, 47, 1409.

21. Einbond, L. S.; Reynertson, K. A.; Luo, X.; Basile, M. J.; Kennelly, E. J.; Food Chem. 2004, 84, 23.

22. Veigas, J. M.; Narayan, M. S.; Laxman, P. M.; Neelwarne, B.; Food Chem.2007, 105, 619 .

23. Giusti, M. M.; Rodriguez-Saona, L. E.; Griffin, D.; Wrolstad, R. E.; J. Agric. Food Chem. 1999, 47, 4657.

24. Idaka, E.; Suzuki, K.; Yamakita, H.; Ogawa, T.; Kondo, T.; Goto, T.; Chem. Lett.1987, 145

25. Adjé, F.; Lozano, Y. F.; Lozano, P.; Adima, A.; Chemat, F.; Gaydou, E. M.; Ind. Crop Prod. 2010, 32, 439.

26. Saleh, N. A. M.; Ishak, M. S.; Phytochemistry 1976, 15, 835. 
ANTOCIANINAS EM EXTRATOS VEGETAIS: APLICAÇÃO EM TITULAÇÃO ÁCIDO-BASE E IDENTIFICAÇÃO VIA CROMATOGRAFIA LÍQUIDA/ESPECTROMETRIA DE MASSAS

Wesson Guimarães, Maria Isabel Ribeiro Alves e Nelson Roberto Antoniosi Filho*

Instituto de Química, Universidade Federal de Goiás, CP 131, 74001-970 Goiânia - GO, Brasil

Tabela 1S. Aplicação de indicadores naturais na determinação indireta do teor de carbonato em amostra de calcário $(n=3)$

\begin{tabular}{|c|c|c|c|c|}
\hline Indicador & $\begin{array}{l}\text { Volume } \\
\text { de } \mathrm{NaOH} \\
(\mathrm{mL})^{*}\end{array}$ & $\begin{array}{c}\text { Teor de } \\
\text { carbonato } \\
(\%)\end{array}$ & $\begin{array}{l}\text { Exatidão com } \\
\text { relação à } \\
\text { fenolftaleína } \\
(\%)\end{array}$ & $\begin{array}{c}\text { Exatidão } \\
\text { com relação } \\
\text { à potencio- } \\
\text { metria }(\%)\end{array}$ \\
\hline Jabuticaba & $5,80 \pm 0,05$ & 51,77 & 97,7 & 96,6 \\
\hline Jambolão & $5,50 \pm 0,05$ & 52,97 & 100,0 & 98,9 \\
\hline Petúnia & $5,45 \pm 0,05$ & 53,17 & 100,4 & 99,2 \\
\hline Flamboyant & $5,60 \pm 0,10$ & 52,57 & 99,2 & 98,1 \\
\hline Pata de Vaca & $5,45 \pm 0,05$ & 53,17 & 100,4 & 99,2 \\
\hline Picão & $5,30 \pm 0,05$ & 53,77 & 101,5 & 100,4 \\
\hline Repolho Roxo & $5,50 \pm 0,10$ & 52,97 & 100,0 & 98,9 \\
\hline Quaresmeira & $5,60 \pm 0,05$ & 52,57 & 99,2 & 98,1 \\
\hline Ipê Roxo & $5,50 \pm 0,10$ & 52,97 & 100,0 & 98,9 \\
\hline Lobeira & $5,40 \pm 0,05$ & 53,37 & 100,7 & 99,6 \\
\hline Fenolftaleína & $5,50 \pm 0,05$ & 52,97 & 100,0 & 98,9 \\
\hline Potenciometria* & $5,35 \pm 0,00$ & 53,57 & 101,1 & 100,0 \\
\hline
\end{tabular}

*O pH de neutralização na titulação potenciométrica foi de 7,3.

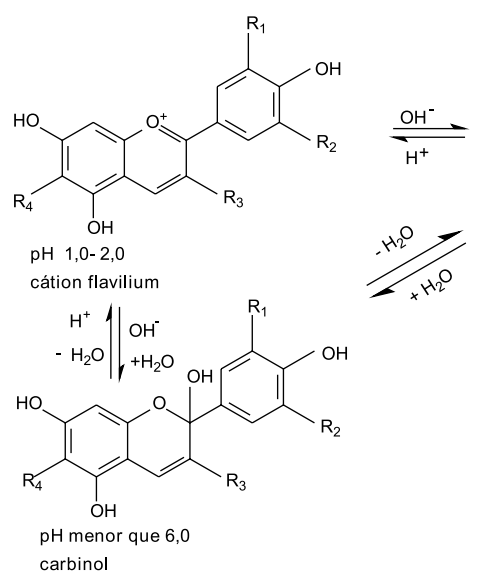<smiles>[R5]c1cc2c(O)c([R4])c(=O)cc-2oc1-c1cc([R])c(O)c([R2])c1</smiles><smiles>[R3]c1cc2c(O)c([R])c(=O)cc-2oc1-c1cc([R])c([O-])c([R2])c1</smiles><smiles>[R]c1cc2c([O-])c([R])c(=O)cc-2oc1-c1cc([R1])c([O-])c([R2])c1</smiles>

$\mathrm{pH} 11,0-12,0$ anidrobase<smiles>[R]C(=Cc1c([O-])cc([O-])c([R])c1[O-])C(=O)c1cc([R])c([O-])c([18OH])c1</smiles>

Figura 1S. Estruturas das antocianidinas em função do $\mathrm{pH}$ 